\title{
XLIV. Glacier-grains
}

\section{R. M. Deeley}

To cite this article: R. M. Deeley (1895) XLIV. Glacier-grains, Philosophical Magazine Series 5, 39:240, 453-455, DOI: $10.1080 / 14786449508620742$

To link to this article: http://dx.doi.org/10.1080/14786449508620742

$$
\text { 曲 Published online: } 08 \text { May } 2009 .
$$

Submit your article to this journal

Џll Article views: 2

Q View related articles $\asymp$ 
are of considerable amplitude, the equations of motion cannot be regarded as sensibly linear ; and accordingly it is to be expected that if two sources of sornd are brought closer together, the intensity of the difference-tone will increase. I have used two stopped organ-pipes of white metal giving the notes $e^{\prime}$ and $g^{\prime}$, the difference-tone being consequently $\mathrm{C}$. The pipes are connected to a well-weighted organ-bellows by flexible rubber tubes, and the distance between them can be varied at will from a few feet to a couple of inches (the walls of the two pipes being then in contact). It is best for the listener to be stationed in a distant room, so that the sound which reaches him is only of moderate intensity, while the comparatively small distances through which the pipes are moved does not appreciably affect the sounds which they individually send to his ear. "The bellows being filled, the sounding pipes are held alternately far apart and near together, and each time, as they nearly upproach one another, the difference-tone $\mathrm{C}_{1}$ is heard to boom out with greatly increased intensity. From this, I would suggest, we are to infer that the difference-tone has a real objective existence.

(Further experiments have not confirmed this result. Fiven Prof. Rücker's very sensitive arrangement of interferencebands failed to show any objective difference-tone from the two organ-pipes, suitably tuned. An attempt will be made to deal with the subject more fully in a subsequent paper.)

\section{Glacier-Grains.}

To the Editors of the Philosophical Magazine.

Gentlemen, 10 Charnwood Street, Derby, April 3, 1895.

TN 1888 I communicated to the February No. of the Phil. 1 Mag. a short paper on glacier motion. Since then I have had an opportunity of examining, in company with Mr. G. Fletcher, F.G.S., the structure of some of the largest Swiss and Norwegian glaciers. The results of our investigation are given in a paper printed in the April number of the Geological Magazine for the current year.

In it we show that the small granular particles of ice resulting from the partial melting and refreezing of the snow, and also the minute crystal particles collected during frosty sunless days, in course of time, when they have become welded by pressure into a compact mass, undergo a striking change. The graater number of the granules and crystalline particles disappear, the molecules composing them going to build up a comparatively small number of large crystalline

Phil. Mag. S. 5. Vol. 39. No. 240. May 1895. $2 \mathrm{H}$ 
particles. In our paper we remark *: "Although it is not quite clear why some of the grains should increase in size and others disappear, the transference of the molecules from crystal to crystal offers no difficulty. ...."

Since this was written I have been led to think that the known laws regulating surface-tension phenomena perhaps afford an explanation for the disappearance of the smaller granules and the growth of the larger ones.

Glacier-ice consists of a kind of conglomerate formed of glacier-grains. These grains have very irregular outlines Fig. 1.

$\left(\frac{1}{2}\right)$ Horizontal slice from the Fismeer of Untergrindelwald Glacier.

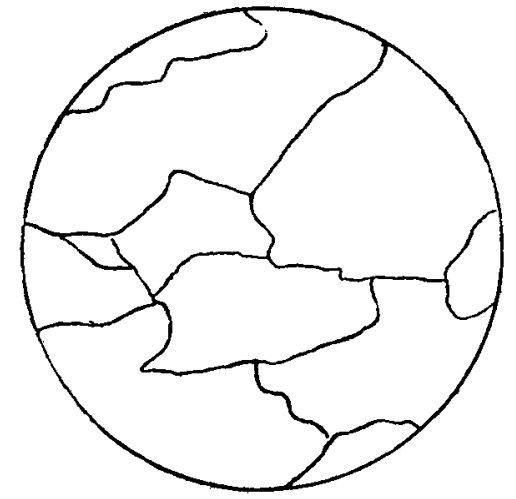

Fig. 2.

(1) Vertical section from Mer de Glace Glacier.

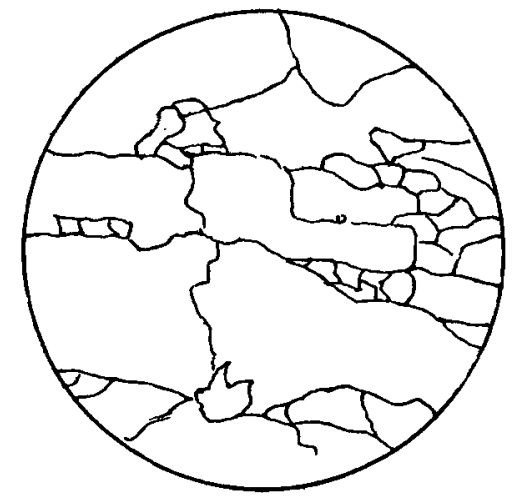

and fit closely together. Figs. 1 and 2 are drawings of slices of glacier-ice as seen under polarized light.

Fig. 2 is a sample of veined ice, the crystalline particles having been sheared by the motion of the glacier.

* Geol. Mag. April 1895, p. 155. 
Botween each grain and its neighbours there is a true surface, the tension of which probably depends in some measure upon the relationship of their axes to each other.

Now we know that a by no means unimportant portion of the energy of a solid body depends upon its surface area ; and I would suggest also that it depends in some measure upon the surfaces separating the crystal units, of which it is composed, from each other, even when they are of similar composition.

In a block of glacier-ice, therefore, or in a block of granite, the total energy depends, not only upon its temperature and volume, but also upon the energy of the surface-tensions of its component grains, whether they be similar or dissimilar in composition.

Now it is an important theorem of Dynamies that, for the stable equilibrium of a system, the potential energy of the whole must be a minimum. For instance, when immiscible liquids are intimately mixed, work is done in increasing their surface-energy, and the energy thus rendered potential serves to again separate them. Glacier-ice is in much the same condition. Its potential energy is always tending to a minimum, a condition which can only be reached by the disappearance of the interfaces between the crystal-grains. Being viscous, it is unable to do more than delay the disappearance of the interfaces, and the grains would continue to grow larger and larger with the lapse of time were it not for the fact that they are broken in the production of the ribboned or veined structure.

For the same reason masses of all liquids possessing structure, whatever their viscosities may be, eventnally become single crystalline particles.

Yours truly,

R. M. Deeley.

XLV. On the Kinetic Interpretation of the Dissipation Function. By Dr. Ladislas Natanson, Professor of Natural Philosophy, University of Cracow*.

1. $\mathrm{N}$ the following paper we consider a fluid medium from 1 Maxwell's point of view (see the paper "On the Dynamical Theory of Gases," 'Scientific Papers,' ii. 26) ; we suppose it to be composed of a great number of moving molecules. Let $\xi, \eta, \zeta$ be the components of the individual (or "molecular") velocity of a molecule; and let $u, v, w$ be

* Translated from " $R$ szprawy" (Tranzactions) of the Cracow Academy of Sciences, Math. and Phys. Section, vol, xxix. Communicated by the Author. 